\title{
Opportunistic Pathogens Mycobacterium Avium Complex (MAC) and Legionella spp. Colonise Model Shower
}

\author{
Harriet Whiley ${ }^{1, *}$, Steven Giglio ${ }^{2}$ and Richard Bentham ${ }^{1}$
}

1 School of the Environment, Health and the Environment, Flinders University, GPO BOX 2100, Adelaide 5001, Australia; E-Mail: richardhbentham@gmail.com

2 Healthscope Pathology SA, 1 Goodwood Rd, Wayville 5034, South Australia;

E-Mail: Steven.Giglio@healthscope.com.au

* Author to whom correspondence should be addressed; E-Mail: harriet.whiley@flinders.edu.au; Tel.: +61-8-72218585; Fax: +61-8-72218590.

Academic Editor: Lawrence S. Young

Received: 4 June 2015 / Accepted: 23 July 2015 / Published: 24 July 2015

\begin{abstract}
Legionella spp. and Mycobacterium avium complex (MAC) are opportunistic pathogens of public health concern. Hot water systems, including showers, have been identified as a potential source of infection. This paper describes the colonization of Legionella and MAC on the flexible tubing within a model potable shower system, utilizing thermostatic mixing and a flexible shower head. A MAC qPCR method of enumeration was also developed. MAC and Legionella spp. were detected within the biofilm at maximum concentrations of $7.0 \times 10^{4}$ and $2.0 \times 10^{3}$ copies $/ \mathrm{cm}^{2} \mathrm{PVC}$ tubing respectively. No significant changes were observed between sample of the flexible shower tubing that dried between uses and those that remained filled with water. This suggested the "unhooking" showerheads and allowing them to dry is not an effective method to reduce the risk of Legionella or MAC colonisation.
\end{abstract}

Keywords: Mycobacterium avium complex (MAC); non-tuberculous mycobacterium (NTM); Legionella spp.; Legionella pneumophila; potable water; showers; model; biofilm 


\section{Introduction}

Contaminated shower systems are a major public health concern as they may result in constant exposure to potentially harmful microorganisms [1]. Showers provide an ideal niche for bacterial biofilm formation, which enables both pathogenic and opportunistic microorganisms to accumulate in large numbers. These microorganisms are then dispersed into the passing water and aerosolised by the showerhead, providing means for inhalation deep into the respiratory tract [2]. Mycobacterium avium complex (MAC) and Legionella spp. are opportunist human pathogens, that have been associated with contaminated shower systems as a source of infection $[3,4]$.

MAC causes a wide spectrum of disease including: fibrocavitary lung disease [5], fibronodular bronchiectasis [6], pulmonary nodules simulating lung cancer [7], hypersensitivity pneumonitis [8], cutaneous skin [9] and soft tissue infection particularly in post-surgery patients [10], cervical lymphadenitis in children [11], gastrointestinal tract and disseminated infection in immune compromised patients [12], and debatably Crohns disease [13]. In most countries MAC is not a notifiable disease and its wide range of clinical manifestations makes it is difficult to accurately estimate disease prevalence; however, it is generally accepted that the incidence of MAC infection is increasing [14-16].

One hypothesis is that this increased prevalence is related to the change in our hygiene habits from bathing to showering [17]. This was further supported by a study in Japan which investigated the distribution of MAC in domestic households. MAC was only recovered from bathrooms but not from other sites of residences and the prevalence of detection in the bathrooms of patients with pulmonary MAC was significantly higher than that in healthy volunteers' bathrooms [18].

Legionella spp. is the causative pathogen of Legionellosis which includes Legionnaires' disease, a Legionella derived pneumonic infection, and Pontiac fever, an acute febrile illness [19]. The exact incidence of Legionellosis worldwide is unknown due to differences in diagnosis and reporting methods. In the United States it is estimated that 8000 to 18,000 people contract Legionnaires' disease annually, with surveillance data from the Centres for Disease Control and Prevention (CDC) indicating that less than $10 \%$ of estimated cases are reported to local and state health officials [20]. Studies investigating nosocomial outbreaks of Legionnaires disease have identified contamination of hospital water distribution systems [21,22] and specifically shower heads as a likely source of infection [23].

The aim of this study was to develop a model potable warm water system to simulate a shower utilizing thermostatic mixing and a flexible shower head, as typically found in hospitals aged care facilities and domestic households.

\section{Experimental Model and Methods}

The model (Figure 1) was constructed so that two sections of each PVC flexible tubing replicate (with an internal diameter of $10 \mathrm{~mm}$ as commonly used in shower heads) could be destructively sampled. Sample 1 was positioned in the " $u$ bend" of the flexible tubing and remained filled with water between uses; whereas, sample 2 was positioned near the top section of tubing which drained dry between uses. This was done to represent a flexible shower head left on its hook and to determine if allowing flexible shower heads to drain in-between uses has an effect on the risk for Legionella or MAC colonisation. 
The novelty of our approach is the qPCR quantification and study of temporal variations of these opportunist pathogens in operating showers systems. This includes showers that have been allowed to drain which have been suggested to be less likely to be colonised than those with residual water in them. This study has demonstrated that there is no significant change to population densities in frequently used hoses whether left to drain or "hung up". To our knowledge this has not been previously reported.

Potable water was added to the reservoir and the temperature of the water was maintained at $35^{\circ} \mathrm{C}$ to represent thermostatic mixing. The flow rate in each PVC tubing was $9 \mathrm{~L} / \mathrm{min}$ as considered the maximum flow rate for water saving shower heads. Water was pumped for $3 \mathrm{~min}$ a day for 5 days on, two days off, for 6 weeks to allow the biofilm to establish. Once the system had established the detachable sampling sections of tubing were replaced with clean tubing and the water continued to be pumped for $3 \mathrm{~min}$ a day for 5 days on, two days off. This temporal water usage pattern was selected as it represents the non-continuous usage that is likely for hospital showers. Swab samples were taken from the pipe surface not from the bathing medium to characterise the established biofilm population. Sample sections of tubing were removed at weekly intervals to investigate the time that it took for biofilm to establish (each of the five tubing replicates represented another week of biofilm formation). This sampling timeline was repeated three times. On test days the sections of tubing were removed prior to flushing for that day. Once a sample was removed the tubing was sliced in half and swabbed with a sterile cotton tip. The two halves of tubing and the sterile swab were submerged in $45 \mathrm{~mL}$ of sterile water and mixed by inversion for $30 \mathrm{~s}$, vortexed for $60 \mathrm{~s}$ and sonicated at $46 \mathrm{kHz}$ for $3 \mathrm{~min}$. The tubing and cotton tips were then removed with sterile tweezers.

qPCR was chosen as the enumeration method over culture, as culture is notoriously inaccurate and can return false negative results [24]. Culture is especially problematic for MAC, with very poor recoveries and long incubation periods that require molecular confirmation of presumptive culture results $[25,26]$. DNA was extracted from $40 \mathrm{~mL}$ of each water sample using the BIO-RAD Aquadien ${ }^{\mathrm{TM}}$ Kit following manufacturer's instructions (Bio-Rad Laboratories, Inc., Hercules, CA, USA). Legionella spp. were enumerated using a previously described qPCR method, using primers JFP 5'-AGGGTTGATAGGTTAAGAGC-3' and JRP 5'-CCAACAGCTAGTTGACATCG-3' [27]. MAC qPCR was developed using previously described primers MACF (5'-CCCTGAGACAACACTCGGTC-3') and MACR (5'-ATTACACATTTCGATGAACGC-3') [28].The limit of detection of the MAC assay was determined using a series on 1 in 10 dilutions $\left(5 \times 10^{0}-5 \times 10^{9}\right.$ copies/reaction $)$ of purified PCR product using the Corbett Research liquid handling system. The limit of detection was 50 copies/reaction which equated to a limit of detection of 96 copies $/ \mathrm{cm}^{2}$.

The optimised $25 \mu \mathrm{L}$ reaction volume contained $1 \times$ PCR buffer (Invitrogen), $2.5 \mathrm{mM} \mathrm{MgCl} 2$ (Invitrogen), $2.5 \mathrm{mM}$ SYTO9 fluorescent dye (Invitrogen), $0.2 \mathrm{mM}$ deoxynucleoside triphosphate mix (Invitrogen), $1 \mathrm{U}$ platinum Taq DNA polymerase (Invitrogen), $0.3 \mu \mathrm{M}$ forward primer, $0.3 \mu \mathrm{M}$ reverse primer and $5 \mu \mathrm{L}$ of template DNA. The cycling conditions included an initial hold at $95{ }^{\circ} \mathrm{C}$ for $5 \mathrm{~min}$, followed by 45 cycles consisting of $94{ }^{\circ} \mathrm{C}$ for $10 \mathrm{~s}, 60{ }^{\circ} \mathrm{C}$ for $20 \mathrm{~s}$, and $72{ }^{\circ} \mathrm{C}$ for $20 \mathrm{~s}$. 


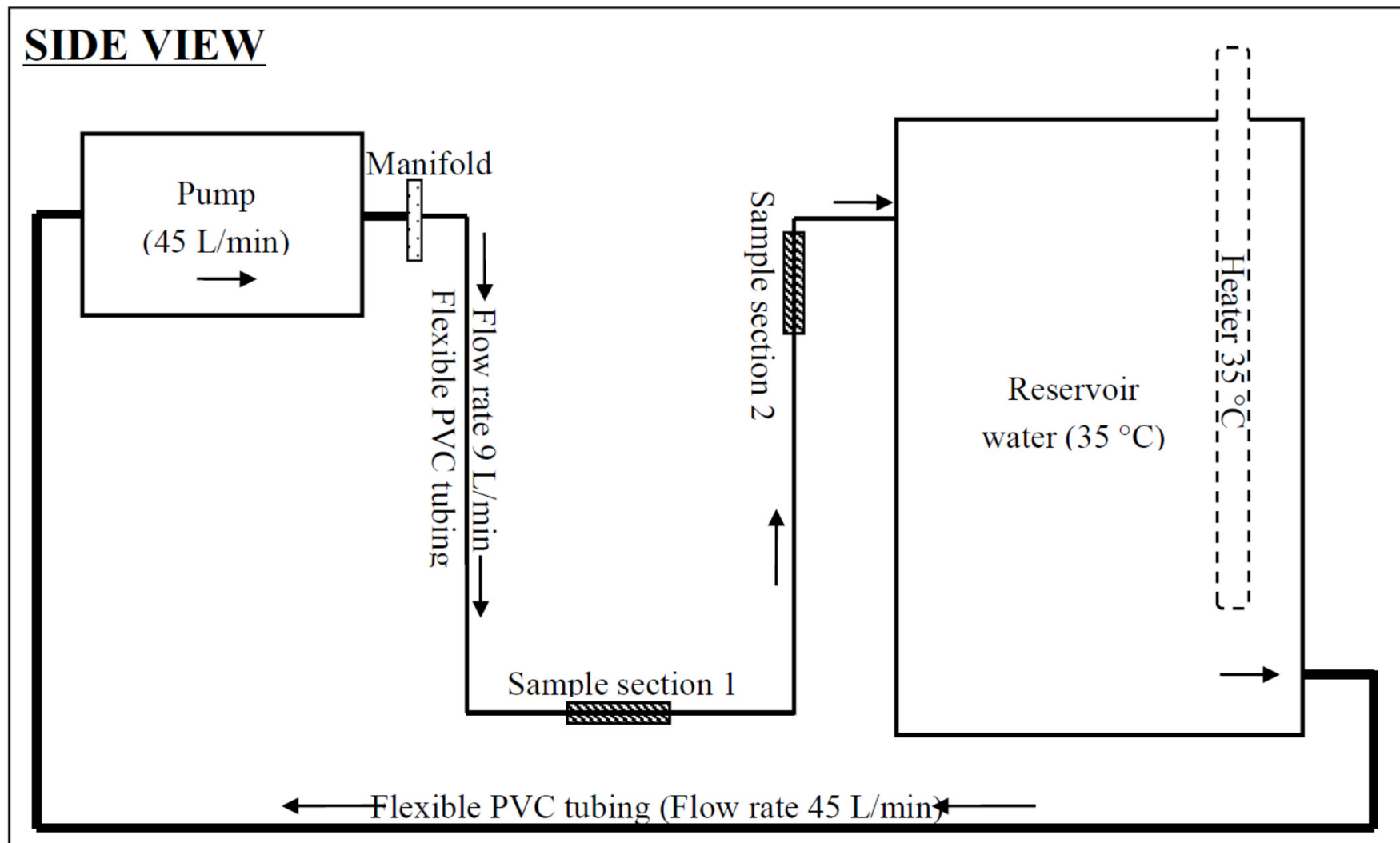

\section{TOP VIEW}

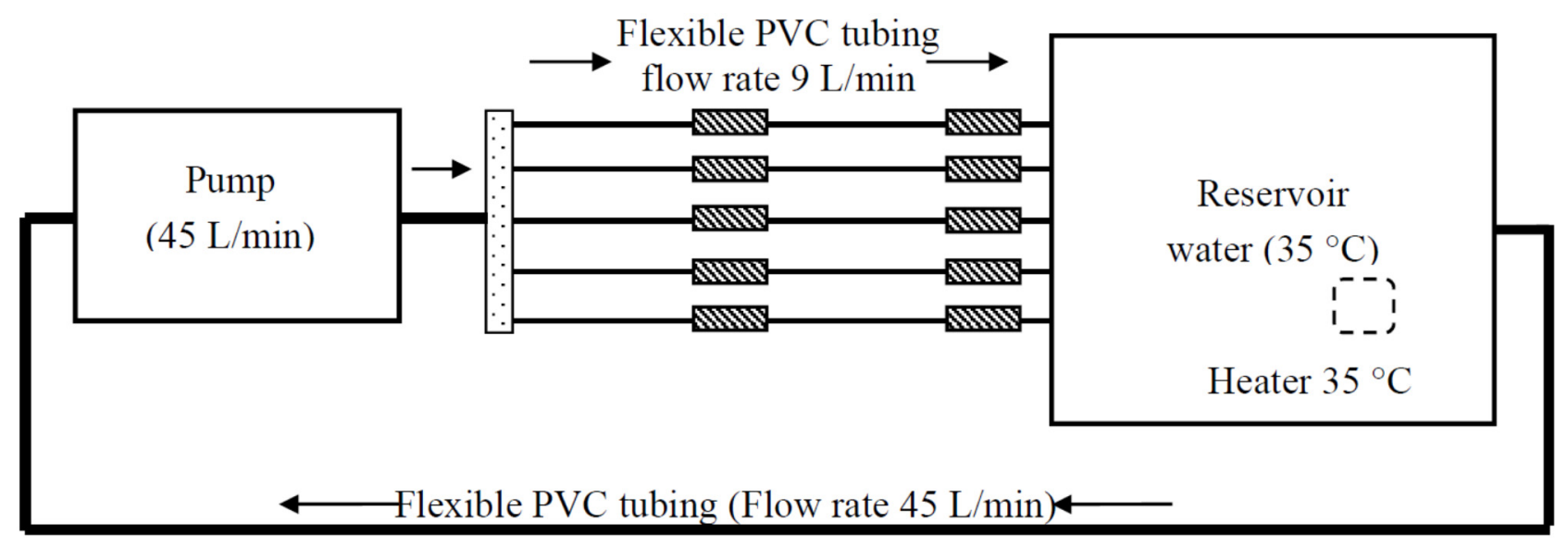

\section{LEGEND}

Manifold (water flow rate goes from $45 \mathrm{~L} / \mathrm{min}$ in one tube to $9 \mathrm{~L} / \mathrm{min}$ in five separate PVC tubes)

Sample section of tubing $(90 \mathrm{~mm}$ of PVC tubing attached using connectors which utilized $15 \mathrm{~mm}$ at each end of the PVC tubing sample. Thus the total sample section was considered to be $60 \mathrm{~mm}$ in length. The internal diameter of tubing was $10 \mathrm{~mm}$ and hence total surface area of sample section was $18.85 \mathrm{~cm}^{2}$ )

Figure 1. Diagram of model potable warm water shower system.

All qPCR reactions were carried out in a RotorGene 3000 (Corbett Research, Sydney, Australia) with data acquisition at $72{ }^{\circ} \mathrm{C}$ on the 6-carboxyfluorescein channel (excitation at $470 \mathrm{~nm}$, detection at $510 \mathrm{~nm}$ ) 
at a gain of 5. Melt curve data was also acquired on this channel at gains of 2 and 5 using a ramping rate of $1{ }^{\circ} \mathrm{C} / 60 \mathrm{~s}$ from $75^{\circ} \mathrm{C}$ to $95^{\circ} \mathrm{C}$. For each reaction the melt curve was analysed and a positive Legionella spp. and MAC was confirmed with a melting temperature $\left(\mathrm{T}_{m}\right)$ of $88 \pm 1^{\circ} \mathrm{C}$ and $85 \pm 1^{\circ} \mathrm{C}$ respectively. Quantification of confirmed amplicons for both MAC and Legionella was performed using the standard curves and linear regression equations generated by the Rotorgene software.

\section{Results and Discussion}

The South Australian potable water added to the model system was not spiked with positive cultures; however, MAC and Legionella spp. were detected at maximum concentrations of $7.0 \times 10^{4}$ and $2.0 \times 10^{3}$ copies $/ \mathrm{cm}^{2}$ of PVC tubing. Although $\mathrm{qPCR}$ does not differentiate between viable and killed cells [29], the ability to colonise the biofilm on PVC tubing indicates viability and suggests their presence in South Australian potable supply. Statistical analyses of results were conducted using Graph $\mathrm{Pad}^{\mathrm{TM}}$ prism 5.0 (Graph Pad software Inc., La Jolla, CA, USA). Kolmogorov-Smirnov normality test of MAC and Legionella copies $/ \mathrm{cm}^{2}$ determined that all samples were not normally distributed. The transformed $\log _{10}$ of MAC and Legionella copies/ $\mathrm{cm}^{2}$ data was then tested again using the Kolmogorov-Smirnov normality test and were found to be normally distributed. The $\log _{10}$ of results were then used for all further statistical analyses and are presented in Figures 2 and 3. A one way ANOVA of the $\log _{10}$ of the $\mathrm{MAC}$ and Legionella copies $/ \mathrm{cm}^{2}$ was then conducted to determine if the means of each time point were significantly different to the $95 \%$ confidence level. The resulting $\mathrm{P}$ values were 0.0032 and 0.0419 respectively $(p<0.05)$ indicating that they were significantly different and the concentration of biofilm changed over time, although no trends were observed. For each of the three replicates, an unpaired T-test of MAC and Legionella numbers at sample 1 (low sample) and sample 2 (high sample) over each time period was conducted to demonstrate that the mean $\log _{10} \operatorname{MAC}(p=0.5646,0.8825,0.8967)$ and Legionella $(p=0.3150,0.0541,0.1704)$ copies $/ \mathrm{cm}^{2}$ detected at sample 1 and sample 2 of the same time point were not significantly different. This suggests that the Legionella and MAC were not affected by desiccation between flushing and that the once a day flushing did not provide sufficient shearing force to remove biofilm or prevent its formation. Thus "unhooking" flexible shower heads and allowing them to dry does not reduce the amount of Legionella formation. 


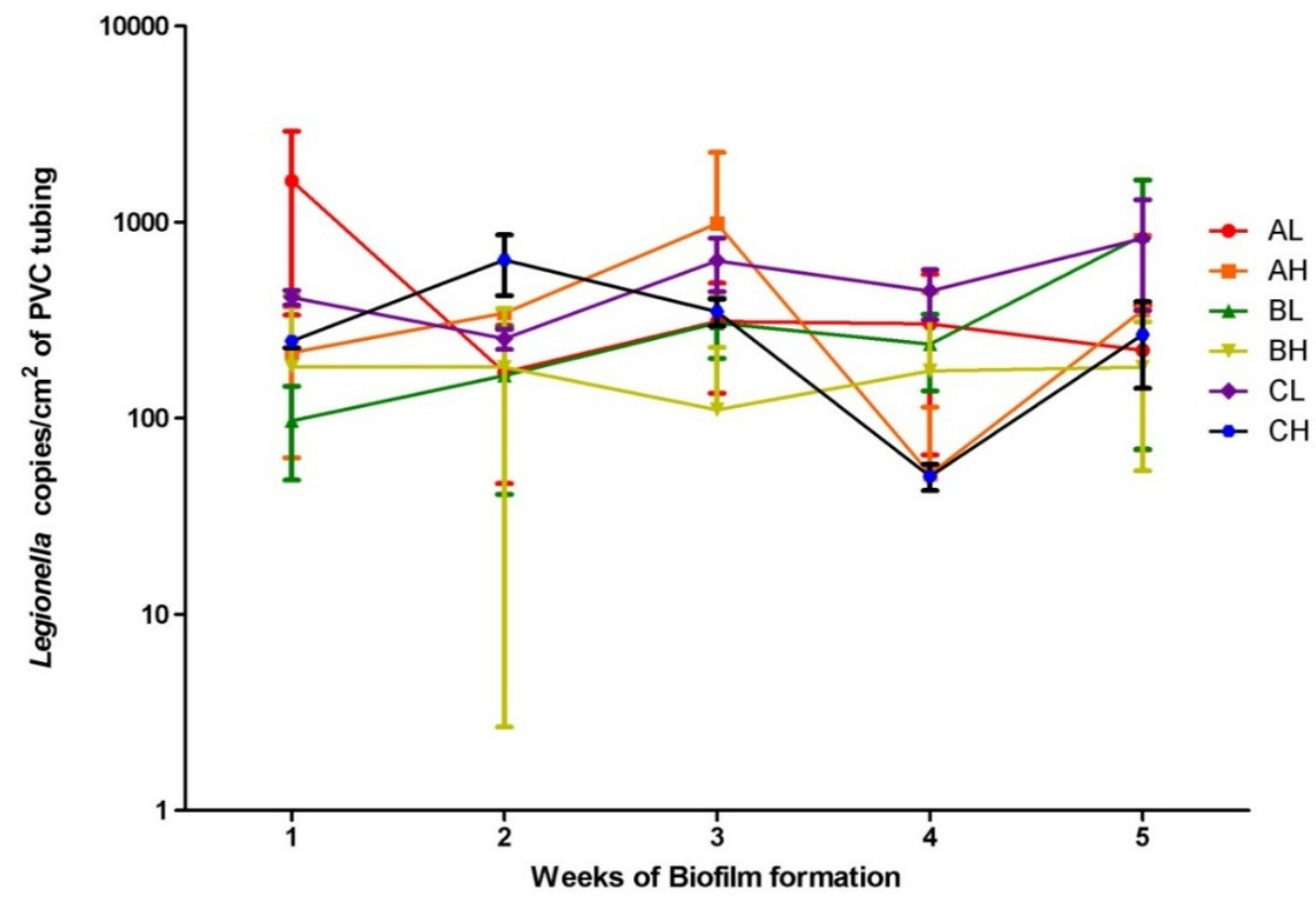

Figure 2. Legionella spp. copies $/ \mathrm{cm}^{2}$ of PVC tubing and standard deviations $(\mathrm{n}=3)$ of sample 1 (L) and sample $2(\mathrm{H})$ sample sections from the three sampling replicates (A, B and C) from the model potable water system over 5 weeks of biofilm formation displayed on a logarithmic scale.

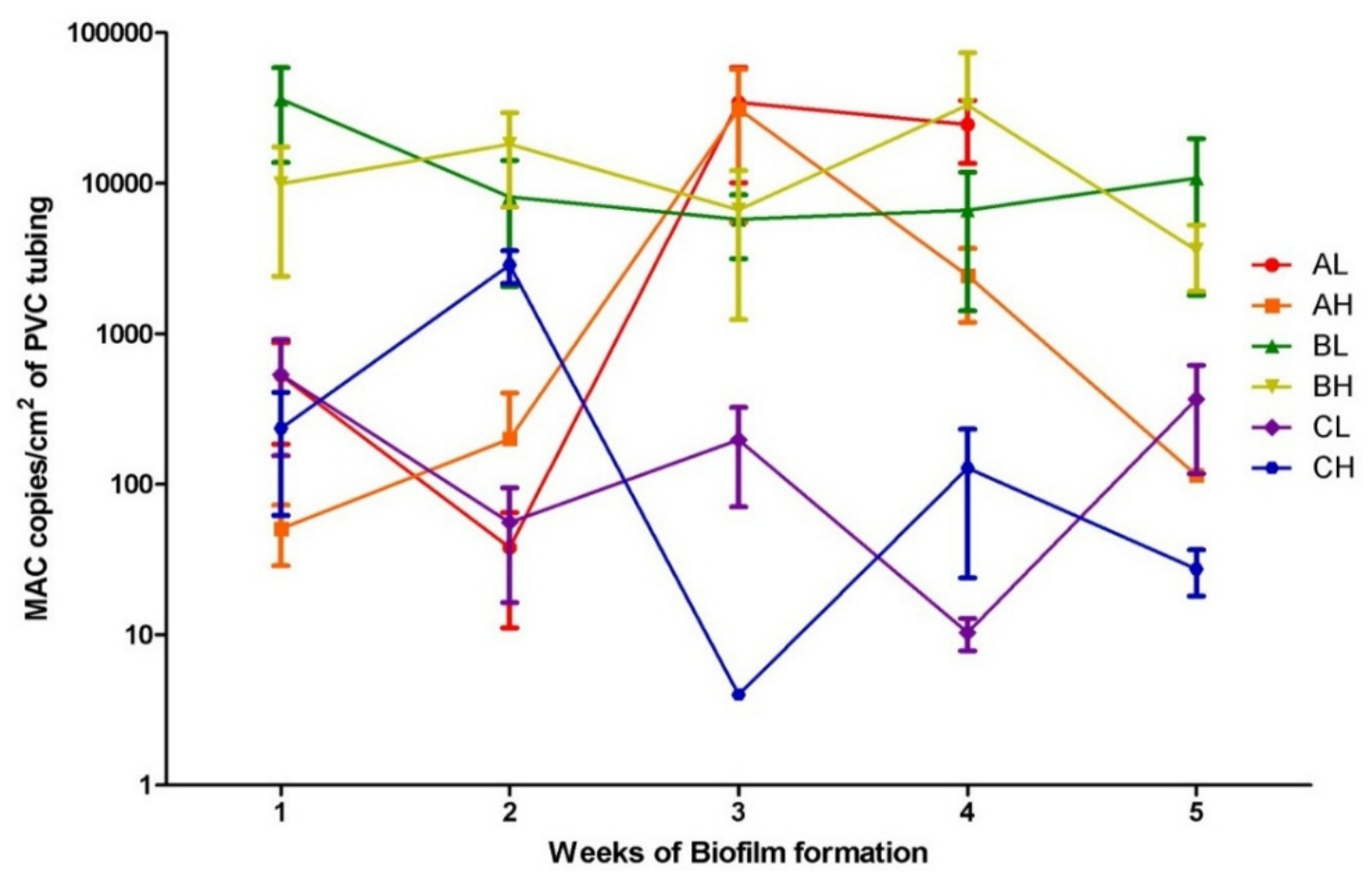

Figure 3. Mycobacterium avium complex (MAC) copies $/ \mathrm{cm}^{2}$ of $\mathrm{PVC}$ tubing and standard deviations $(\mathrm{n}=3)$ of sample $1(\mathrm{~L})$ and sample $2(\mathrm{H})$ sample sections from the three sampling replicates (A, B and C) from the model potable water system over 5 weeks of biofilm formation displayed on a logarithmic scale. 


\section{Conclusions}

This model shower system demonstrated the potential of MAC and Legionella spp. to colonise the plastic tubing in flexible shower heads and that temporal water usage had no effect on their colonisation. Also for each sampling time point, there was no significant difference in the concentration of Legionella or MAC sampled from a tubing section that was allowed to dry out and a section that was filled with water in between usages. This suggests that allowing shower tubing to dry between usages will not reduce the risk for Legionella or MAC colonisation. This information is useful for future consideration of environmental factors influencing the contamination of shower systems in aged care facilities hospitals and domestic households using flexible shower heads.

\section{Author Contributions}

SG and RB conceived and participated in its design and coordination. SG developed the qPCR methods and provided trouble shooting for all molecular work. HW developed model design and carried out the laboratory work including model construction and qPCR analysis. HW drafted the manuscript. All authors read and approved the final manuscript.

\section{Conflicts of Interest}

The authors declare no conflict of interest.

\section{References}

1. Lindsay, D.; Holy, A. Bacterial biofilms within the clinical setting: What healthcare professionals should know. J. Hosp. infect. 2006, 64, 313-325.

2. Feazel, L.M.; Baumgartner, L.K.; Peterson, K.L.; Frank, D.N.; Harris, J.K.; Pace, N.R. Opportunistic pathogens enriched in showerhead biofilms. Proc. Natl. Acad. Sci. 2009, 106, 16393-16399.

3. Zmirou-Navier, D.; Remen, T.; Bauer, M.; Deloge-Abarkan, M.; Tossa, P.; Mathieu, L. Legionella in shower aerosols and pontiac fever among health workers and residents in nursing homes. Epidemiology 2007, 18, S50, doi:10.1097/01.ede.0000276578.64205.09.

4. Falkinham, J.O.; Iseman, M.D.; de Haas, P.; van Soolingen, D. Mycobacterium avium in a shower linked to pulmonary disease. J. Water Health 2008, 6, 209-213.

5. Field, S.K. Mycobacterium avium complex pulmonary disease in patients without hiv infection. Chest 2004, 126, 566.

6. Huang, J.H.; Kao, P.N.; Adi, V.; Ruoss, S.J. Mycobacterium avium-intracellulare pulmonary infection in hiv-negative patients without preexisting lung disease. Chest 1999, 115, 1033-1040.

7. Lakhanpal, A.; Arfon, S.; McKeon, D.J. So, they thought it was all over. BMJ Case Rep. 2011, 2011.

8. Marras, T.K.; Wallace, R.J.; Koth, L.L.; Stulbarg, M.S.; Cowl, C.T.; Daley, C.L. Hypersensitivity pneumonitis reaction to mycobacterium avium in household water. Chest 2005, 127, 664-671.

9. Sugita, Y. Familial cluster of cutaneous mycobacterium avium infection resulting from use of a circulating, constantly heated bath water system. Br. J. Dermatol. 2000, 142, 789. 
10. Karakousis, P.C.; Moore, R.D.; Chaisson, R.E. Mycobacterium avium complex in patients with hiv infection in the era of highly active antiretroviral therapy. The Lancet 2004, 4, 557-565.

11. Thegerström, J.; Friman, V.; Nylén, O.; Romanus, V.; Olsen, B. Clinical features and incidence of mycobacterium avium infections in children. Scand. J. Infect. Dis. 2008, 40, 481-486.

12. Nightingale, S.D.; Byrd, L.T.; Southern, P.M.; Jockusch, J.D.; Cal, S.X.; Wynne, B.A. Incidence of mycobacterium avium-intracellulare complex bacteremia in human immunodeficiency virus (hiv) positive patients. J. Infect. Dis. 1992, 165, 1082-1085.

13. Naser, S.A.; Ghobrial, G.; Romero, C.; Valentine, J.F. Culture of mycobacterium avium subspecies paratuberculosis from the blood of patients with crohn's disease. The Lancet 2004, 364, 1039-1044.

14. Adjemian, J.; Olivier, K.N.; Seitz, A.E.; Holland, S.M.; Prevots, D.R. Prevalence of nontuberculous mycobacterial lung disease in U.S. Medicare beneficiaries. Am. J. Respir. Crit. Care Med. 2012, $185,881-886$.

15. Al-Houqani, M.; Jamieson, F.; Mehta, M.; Chedore, P.; May, K.; Marras, T.K. Aging, copd, and other risk factors do not explain the increased prevalence of pulmonary mycobacterium avium complex in ontario. Chest 2012, 141, 190-197.

16. Marras, T.K.; Daley, C.L. Epidemiology of human pulmonary infection with nontuberculous mycobacteria. Clin. Chest Med. 2002, 23, 553-567.

17. O’Brien D.P.; Currie B.J.; Krause V.L. Nontuberculous mycobacterial disease in northern australia: A case series and review of the literature. Clin. Infect. Dis. 2000, 31, 958-967.

18. Nishiuchi, Y.; Maekura, R.; Kitada, S.; Tamaru, A.; Taguri, T.; Kira, Y.; Hiraga, T.; Hirotani, A.; Yoshimura, K.; Miki, M., et al. The recovery of mycobacterium avium-intracellulare complex (mac) from the residential bathrooms of patients with pulmonary mac. Clin. Infect. Dis. 2007, 45, 347-351.

19. Buchbinder, S.; Trebesius, K.; Heesemann, Jr. Evalution of detection of legionella spp. In water samples by fluorescence in situ hybridization, pcr amplification and bacterial culture. Int. J. Medical Microbiol. 2002, 292, 241-245.

20. Pond, K. Water recreation and disease. In Plausibility of Associated Infections: Aute Effects, Sequelae and Mortality; IWA Publishing on behalf of World Health Organization (WHO): London, UK, 2005.

21. Kool, J.; Bergmire-Sweat, D.; Butler, J.; Brown, E.; Peabody, D.; Massi, D.; Carpenter, J.; Pruckler, J.; Robert, B.; Fields, B. Hospital characteristics associated with colonization of water systems by legionella and risk of nosocomial legionnaires' disease: A cohort study of 15 hospitals. Infect. Control Hosp. Epidemiol. 1999, 20, 798-805.

22. Wellinghausen, N.; Frost, C.; Marre, R. Detection of legionellae in hospital water samples by quantitative real-time lightcycler pcr. Appl. Environ. Microbiol. 2001, 67, 3985-3993.

23. Cordes, L.; Wiesenthal, A.; Gorman, G.; Phair, J.; Sommers, H.; Brown, A.; Yu, V.; Magnussen, M.; Meyer, R.; Wolf, J., et al. Isolation of legionella pneumophila from hospital shower heads. Ann. Intern. Med. 1981, 94, 195-197.

24. Whiley, H.; Taylor, M. Legionella detection by culture and qpcr: Comparing apples and oranges. Crit. Rev. Microbiol. 2014. 
25. Eaton, T.; Falkinham, J.O.; Aisu, T.O.; Daniel, T.M. Isolation and characteristics of mycobacterium avium complex from water and soil samples in uganda. Tuber. Lung Dis. 1995, 76, 570-574.

26. Han, X.Y.; Tarrand, J.J.; Infante, R.; Jacobson, K.L.; Truong, M. Clinical significance and epidemiologic analyses of mycobacterium avium and mycobacterium intracellulare among patients without aids. J. Clin. Microbiol. 2005, 43, 4407-4412.

27. Giglio, S.; Monis, P.T.; Saint, C.P. Legionella confirmation using real-time pcr and syto9 is an alternative to current methodology. Appl. Environ. Microbiol. 2005, 71, 8944-8948.

28. Park, H.; Jang, H.; Kim, C.; Chung, B.; Chang, C.; Park, S.K.; Song, S. Detection and identification of mycobacteria by amplification of the internal transcribed spacer regions with genus- and species-specific pcr primers. J. Clin. Microbiol. 2000, 38, 4080.

29. Yáñez, M.A.; Nocker, A.; Soria-Soria, E.; Múrtula, R.; Martínez, L.; Catalán, V. Quantification of viable legionella pneumophila cells using propidium monoazide combined with quantitative pcr. J. Microbiol. Methods 2011, 85, 124-130.

(C) 2015 by the authors; licensee MDPI, Basel, Switzerland. This article is an open access article distributed under the terms and conditions of the Creative Commons Attribution license (http://creativecommons.org/licenses/by/4.0/). 